\title{
OPEN Author Correction: Gate Tuning of Synaptic Functions Based on Oxygen Vacancy Distribution Control in Four-Terminal $\mathrm{TiO}_{2-x}$ Memristive Devices
}

\section{Zenya Nagata, Takuma Shimizu, Tsuyoshi Isaka, Tetsuya Tohei, Nobuyuki Ikarashi \& Akira Sakai $\mathbb{C}^{0}$}

Correction to: Scientific Reports https://doi.org/10.1038/s41598-019-46192-x, published online 10 July 2019

This Article contains errors in the Results section.

"Each $I$ - $V$ curve clearly exhibits hysteresis, indicating RS from LRS to HRS for positive sweeps and HRS to LRS for negative sweeps. The current value gradually decreased through repeated $V_{1}$ sweeping in which the sweep rate was decreased step by step. The resistance gradually increased (decreased), showing multilevel values as the $V_{1}$ sweeping process was repeated."

should read:

"Each $I$ - $V$ curve clearly exhibits hysteresis, indicating RS from LRS to HRS for positive sweeps and HRS to LRS for negative sweeps. The current value gradually decreased (increased) through repeated $V_{1}$ sweeping in which the sweep rate was decreased step by step. The resistance gradually increased (decreased), showing multilevel values as the $V_{1}$ sweeping process was repeated."

(i) Open Access This article is licensed under a Creative Commons Attribution 4.0 International License, which permits use, sharing, adaptation, distribution and reproduction in any medium or format, as long as you give appropriate credit to the original author(s) and the source, provide a link to the Creative Commons license, and indicate if changes were made. The images or other third party material in this article are included in the article's Creative Commons license, unless indicated otherwise in a credit line to the material. If material is not included in the article's Creative Commons license and your intended use is not permitted by statutory regulation or exceeds the permitted use, you will need to obtain permission directly from the copyright holder. To view a copy of this license, visit http://creativecommons.org/licenses/by/4.0/.

(C) The Author(s) 2019 